\title{
Bridging Rhetoric and Pragmatics with Relevance Theory
}

Brian N. Larson

Texas A\&M University School of Law, blarson@law.tamu.edu

Follow this and additional works at: https://scholarship.law.tamu.edu/facscholar

Part of the Other Arts and Humanities Commons, Other Communication Commons, Rhetoric and Composition Commons, and the Speech and Rhetorical Studies Commons

\section{Recommended Citation}

Brian N. Larson, Bridging Rhetoric and Pragmatics with Relevance Theory, 69 (Jan Strassheim \& Hisashi Nasu eds., 2018).

Available at: https://scholarship.law.tamu.edu/facscholar/1251

This Book Section is brought to you for free and open access by Texas A\&M Law Scholarship. It has been accepted for inclusion in Faculty Scholarship by an authorized administrator of Texas A\&M Law Scholarship. For more information, please contact aretteen@law.tamu.edu. 


\title{
Bridging Rhetoric and Pragmatics with Relevance Theory
}

\begin{abstract}
In this chapter, I bridge rhetoric and pragmatics, both of which concern themselves with language-in-use and meaning-making beyond formal syntax and semantics. Previous efforts to link these fields have failed, but Sperber and Wilson's relevance theory (RT), an approach to experimental pragmatics grounded in cognitive science, offers the bridge. I begin by reviewing Gricean pragmatics and its incompatibility with rhetoric and cognitive science. I then sketch RT, but importantly, I identify revisions to RT that make it a powerful tool for rhetorical analysis, a cognitive pragmatic rhetorical (CPR) theory. CPR theory strengthens RT by clarifying what it means to be relevant - and irrelevant - in relevance-theoretic terms. Meanwhile, it provides rhetoric a set of principles for its functioning grounded in cognitive science. I conclude with sample CPRtheoretic analyses.
\end{abstract}

\section{Introduction ${ }^{1}$}

Rhetoric and pragmatics were born together in the Athens of the fifth century BCE. In their history of early pragmatics, Nerlich and Clarke (1996) found its roots in Protagoras' identification of the moods or modes of speech ("statement, question and imperative") and in Aristotle's Rhetoric (2007). Protagoras was one of the sophists, philosophers credited with innovation in the teaching of rhetoric in Athens at the time. Contemporary pragmatics focuses on ascribing meaning to utterances, using context to enrich literal or decoded meaning. Rhetoricians are deeply interested in the work that words do, particularly the work of persuasion, regardless of what their literal meaning might be.

Pragmatics "has to do with all context-dependent aspects of meaning 'systematically abstracted away from in the pure semantics of logical form”" (Nerlich/ Clarke 1996, quoting Horn 1992). To the extent that pragmatic theories extend

1 I would like to thank Dr. Alan Gross and Christopher Cocchiarella for helpful comments on earlier drafts of this chapter.

Brian N. Larson, Texas A\&M University School of Law

https://doi.org/10.1515/9783110472509-004 
language study away from code models - the semantics of logical form - they are likely compatible with rhetoric (Bazerman 1988). Indeed, many theorists in rhetoric (Berkenkotter/Huckin 1994; Bhatia 1993), argumentation theory (van Eemeren/Grootendorst 2004; Jacobs 2000), and critical theory (Butler 1997) have employed concepts from pragmatics. As I explain below, though, previous efforts to bridge pragmatics and rhetorical theory, characterizing them as fiancé(e)s (Dascal/Gross 1999) or as antistrophoi (Liu/Zhu 2011), have failed, in part because of the continued focus in many theories of pragmatics on decoding utterances.

My proposed solution may seem ironic: The relevance theory of pragmatics (Sperber/Wilson 1995) has been regarded with skepticism by many contemporary pragmatists, and relevance theory's proponents, Sperber and Wilson, have regarded rhetoric with skepticism. This article argues, nevertheless, that relevance theory (RT) should be the bridge between these fields. With the exception of Oswald (2007; 2011; 2016) and Larson (2016), however, no one has used RT to link them. What's more, some modifications of RT proposed by other scholars need to be synthesized into the model for it to function as a theory of rhetoric and pragmatics.

The result - which I call cognitive pragmatic rhetorical (CPR) theory - provides a framework for communication and rhetorical analysis that is grounded in cognitive science and its insights about communication embodied in part in RT, and it extends RT in ways that explain the production of utterances and clarify what it means to be "relevant" in relevance-theoretic terms. CPR theory, like RT, posits communicative production and interpretation as functions of relevance, the cognitive tendency of humans to seek out the greatest cognitive effects (desired changes in cognitive environment) with the least cognitive effort. CPR represents a practical, non-reductionist framework to analyze meaning - that is, it looks at the (hermeneutical) dynamics of the linguistic and cognitive, semantic and pragmatic, social and psychological, etc., without simplistic reduction to one or the other. Like RT, CPR provides tools for interpretation and analysis and a framework for predictions that can be tested empirically. If it is correct, it can bridge the rhetorical tradition, cognitive science, and philosophy of language.

This chapter takes the following form: After providing three brief, constructed, illustrative examples of language use, I begin by reviewing a dominant model of contemporary pragmatics that I will call classical pragmatics and its incompatibility with rhetoric and cognitive science. I then sketch RT and revisions to it that make it a powerful tool for rhetorical analysis. Finally, I provide CPR-theoretic analyses of these illustrative examples as well as an attested (though possibly apocryphal) rhetorical performance. 


\section{Illustrative examples}

Imagine three communicative exchanges. ${ }^{2}$ In the first, assume that Cyrille and Marc are French siblings, that Marc is seeking the pen of their common aunt, and Cyrille intends to inform him that the pen in question is on the nearby desk:

(1) Marc: Où est la plume de notre tante?

'Where is our aunt's pen?'

(2) Cyrille: La plume de notre tante est sur le bureau.

'Our aunt's pen is on the desk.'

Consider a second exchange: Laura, Carlos, and Maria are American siblings, all in the drawing room at their aunt's home.

(3) Carlos: Where is Aunt Luisa's Mont Blanc pen?

Carlos is a little pompous and exaggerates the French pronunciation of "Mont Blanc" ([mõ blã]), despite the fact that he speaks no French himself. Laura and Maria both speak French.

(4) Laura: La plume de ma tante est sur le bureau.

Maria snickers.

Consider the third exchange: Note first that (4) has reputedly appeared in low-quality commercial language phrasebooks and has been described as practically useless (Wikipedia n.d.). Bill, a linguist, and Anne, a teacher of German, are professionally familiar with these facts, and each expects the other is as well. Note, too, that Anne likes to make a joke and also likes folks to think she is clever.

(5) Bill: What do you think of Smith's new German textbook?

(6) Anne: Où est la plume de ma tante.

Each of the utterances (2), (4), and (6) is human communication, what Wilson and Sperber $(2012,87)$ describe as "a more or less controlled modification by the

2 The reader may find these examples, and perhaps this entire chapter, more tolerable after viewing comedian Eddie Izzard's 'bit' on these sentences: https://www.youtube.com/watch?v=qnJxafaOGbQ 
communicator of the audience's mental landscape - his cognitive environment [...] - achieved in an intentional and overt way". Thus, every human communication is an attempt by the Speaker ${ }^{3}$ to change the Hearer's beliefs about the world, to alter his emotional state, to redirect his goals, or most likely some combination of these three. Note that this inclusion of goals and emotions in people's cognitive environments is not consistent with Wilson and Sperber's usage, a matter I will take up below.

Whether a given communicative performance or exchange can be called "rhetoric" depends on the scope we give to that term. But certainly the paradigmatic instances of rhetoric - oratory and address in the public sphere - are instances of communication in the terms defined above, and any theory explaining the former should not be inconsistent with theories addressing the latter.

Below, I review some basic principles of pragmatics and the relevance theory of Sperber and Wilson. I then describe the extension of Sperber and Wilson by Straßheim, founded in the concepts of relevance and typification from Alfred Schutz (Schutz 1964; 1966; 1973). Finally, I propose CPR theory's conceptions of the cognitive environment and imputed cognitive environment and briefly introduce the CPR-theoretic production and comprehension/interpretation procedures. In each case, I will refer to the three communicative exchanges above.

\section{Pragmatics, cognitive science, and relevance}

The prevailing theories of language-in-use owe much to work in the philosophy of language by Austin (1975), Searle (1970; 1979), and Grice (1989). Taken together, these scholars can be viewed as the founders of what I will refer to here as classical pragmatics ${ }^{4}$; much of the research in that field is grounded in these works or at least sets itself up in response to them. Classical pragmatics explores the notion that meaning cannot be found merely by decoding sentences based on the semantics of words and the manner of their combination (syntax). Rather, scholars of pragmatics assert that meaning must be derived from the application of inference to the products of decoding.

3 I employ the practice of referring to the hypothetical "Speaker" (or "Writer") and "Hearer" (or "Reader") with an initial capital, using feminine pronouns for the former (Speaker=she) and masculine pronouns for the latter (Hearer=he).

4 Not to be confused with Aristotle and Protagoras, mentioned above as originators of some pragmatic ideas in the classical era in Greece. 
Pragmatics generally contrasts the content of a sentence (the domains of syntax and semantics) with the context of an utterance (the domain of pragmatics). Refer back to the illustrative exchanges above. In (1) and (2), Marc can interpret Cyrille's response in (2) simply by decoding ${ }^{5}$ it - applying a compositional analysis to the syntax and semantics of the sentence. In (3) and (4), assuming Aunt Luisa's pen is on the nearby desk, syntax/semantics would say (4) is literally correct in French. It can be decoded - though not by Carlos - to provide the answer to the question in (3). But pragmatics asks what Laura is doing here: why she is responding in a language that Carlos does not understand.

In (5) and (6), Bill can interpret Anne's response in (6) only by reference to the context; in fact, no effort to decode Anne's utterance will yield useful information. Even assuming Bill speaks French, the propositional content of (6) does nothing to answer his question. In fact, decoding the sentence using syntax and semantics is a waste of his interpretive effort. Nevertheless, the context and Bill and Anne's knowledge of each other and their fields is likely to guide him to a correct interpretation - that the text is superficial and useless - perhaps as soon as he hears the first couple words.

Pragmatics, then, busies itself with going beyond code models of language, usually by application of rational (but not logical or demonstrative) inference to utterances in context in order to determine the Speaker's intention. According to Grice (1989), an utterance may encode a speaker's meaning, or it may merely be evidence of her meaning. For Grice $(1989,26)$, "talk exchanges are characteristically, to some degree at least, cooperative efforts - [with] a common purpose or set of purposes, or at least a mutually accepted direction". Grice famously offered his cooperative principle (CP): "Make your conversational contribution such as is required, at the stage at which it occurs, by the accepted purpose or direction of the talk exchange in which you are engaged" (Grice 1989, 26).

The conclusions that the Hearer draws from the inferential process are what Grice calls "implicatures". These are conclusions that the Hearer draws about what the Speaker "implied, suggested, [or] meant" that are different from what the Speaker "said", which is "closely related to the conventional meaning of the words [...] uttered" - that is, the decoded sentence (Grice 1989, 24-25).

Classical pragmatics is focused on decoding and on rational inferences about meaning implicatures. Common to the theories of Searle $(1970 ; 1979)$ and Grice (1989) is the principle that the Hearer should first decode the literal meaning, or "what is said", and then use inference to derive the implicatures only where

5 Let's ignore for the moment that he must resolve the reference our as some person and our aunt's pen as a particular possession of that person. 
the decoded meaning would fail to satisfy the CP. That is, they assume that the meaning of the sentence as decoded is close to the meaning the Speaker intended and that inference bridges the gap. For example, when Bill attempts to interpret Anne's response to his question about the textbook - "Où est la plume de ma tante" (6) - he would first decode it (assuming he understands French) and then, after concluding that the decoded meaning violates the CP, he would apply inference to her utterance, using it merely as evidence of her meaning.

Two things are important to note: First, for many theorists of pragmatics in the classical mode, implicatures are propositions about the world. That is, the goal of inferential interpretation by the Hearer is that he will believe a larger set of (hopefully true) propositions about the world. Thus, after the exchange in which Bill asks "What do you think of Smith's new German textbook?" (5) and Anne answers "Où est la plume de ma tante" (6), Bill could entertain a thought or representation with the content in (7), or at least the content in (8).

(7) 'Smith's new German textbook is superficial and useless.'

(8) 'Anne thinks Smith's new German textbook is superficial and useless.'

As Dascal and Gross (1999) and Liu and Zhu (2011) explain, rhetoric is concerned with the perlocutionary effects (at least persuasive, but perhaps others) of communication, not merely propositional content. In fairness, Grice $(1989,28)$ did not entirely ignore this issue, writing "this specification is, of course, too narrow, and the scheme needs to be generalized to allow for such general purposes as influencing or directing the actions of others". It is unclear, though, how the CP could work to do this.

Second, with few exceptions, classical pragmatics focuses on interpretation, and not production, of utterances. Rhetoric concerns itself very deeply with the effective means of production; it is "an ability, in each particular case, to see the available means of persuasion” (On Rhetoric 1.2.1, Aristotle 2007, 37).

Consequently, classical pragmatics has proven somewhat difficult to reconcile with rhetoric.

Dascal and Gross $(1999,108)$ proposed a "marriage" of pragmatics and rhetoric. They advocated for what they described as a "cognitive theory of rhetoric", but what I would refer to as a rationalist theory of rhetoric. They identified several reasons why other scholars might not hold their peace at the nuptials of these two fields: First among them, Gricean pragmatics is dialogic. Grice discusses two interlocutors, the Speaker and the Hearer, while rhetoric must account for a Speaker with an audience or a Writer composing a text perhaps without a clear awareness who her audience is. Dascal and Gross address this concern by noting that oratory involves a "continuous interchange" between speaker and audience (Dascal/Gross 1999, 109). A second reason for caution: Grice’s Cooperative Princi- 
ple (CP) does not seem to permit misdirection, a common tool in communication and one commonly analyzed by rhetoricians. Thus Dascal and Gross proposed modifying the CP so that it states that only the appearance of cooperation must be maintained.

Liu and Zhu (2011) asserted that Dascal and Gross misdiagnosed a mismatch between pragmatics and rhetoric. In their view, Dascal and Gross failed to note the mismatch: that pragmatics has "foundational principles," such as the CP, but that rhetoric is identified by "modus operandi" such as pathos, êthos, and style (Liu/Zhu 2011, 3408). Liu and Zhu's observation echoes Plato's Socrates, who suggested that rhetoric was not a science or art, not a systematized body of knowledge, but a "knack acquired by routine" (Plato 2004, 463b, p. 30). ${ }^{6}$ Liu and Zhu (2011) proposed rhetoric and pragmatics as antistrophoi - complementary disciplines, but not united in marriage - echoing Aristotle's juxtaposition of rhetoric and dialectics under the same moniker. Consequently, they saw the CP and Grice's maxims as requiring antistrophoi or complements within rhetoric. They proposed the first of these - what they called the "foundational principle in rhetoric" - the Non-Cooperative Principle or NCP. It takes roughly this form: Always proceed or respond without assuming that the other party is being cooperative.

It is difficult, however, to see the NCP as antistrophos to the CP. Instead, they appear to be antitheses. Grice's entire system relies upon the CP for any coherence that it achieves, and yet Dascal and Gross's approach and the NCP entirely undermine it. Resisting an assumption about whether a particular fact about a talk interaction is true is hardly a foundational principle. These efforts fail satisfactorily to bridge pragmatics and rhetoric.

Classical pragmatics has some issues with contemporary cognitive science as well. Contemporary cognitive science suggests that humans (like many other animals) do not routinely engage in the kind of rational inference posited by the founders of classical pragmatics and that their inferences are governed by other forces, including cognitive biases or heuristics and emotions. By "cognitive science," note first that for me cognition means more than demonstrative inference or even rational inference grounded in probabilities and the like: It includes other functions of the mind, such as emotions and cognitive biases (cf. Oswald 2016; Piskorska 2016). Where cognitive science is concerned, I do not mean the first-wave artificial-intelligence models, which viewed the brain as a sort of computer, operating via logical or demonstrative inference on symbols (Newell/ Simon 1976). Nor am I firmly entrenched in the camp of any of the subsequent

6 Not all translations of the Gorgias give "knack” here. Cf. Nichols' translation in Plato (1998, $46)$, which is "experience". 
models of cognition, including connectionism (Churchland 1989), embedded/ embodied cognition (Clark 1997), or dynamical systems theory (Juarrero 1999). I also do not believe it is necessary, when working with Sperber and Wilson's RT, to accept Sperber and Wilson's (2002) notions of massive modularity, under which there are separate modules for "mind-reading" (theory of mind), linguistic communication, non-linguistic communication, argumentation, etc. Rather, I'm committed generally to the principle embraced by all these models that there is a systematicity to human cognition that is worth exploring and understanding and that a theory of communication, whether RT or the one proposed in this chapter, should be consistent with empirical data.

According to Gigerenzer and Brighton $(2009,109)$, the human mind evolved as a toolbox, a set of capacities, to survive in certain environments. Among the important implements in our cognitive toolboxes are heuristics, "fast and frugal" techniques for drawing conclusions or inferences about our environments that are not necessarily rational in any substantive sense. They identified several key heuristics, including the recognition heuristic (if one of two alternatives is recognized, it is preferred) and the fluency heuristic (if two alternatives are recognized, but one is recognized more quickly, it is preferred). Such efforts to minimize cognitive effort are outgrowths of what Simon (1990) called "bounded rationality" there is only so much cognitive effort that a brain can bring to bear on survival problems. Heuristics function as a kind of "procedural rationality" or "ecological rationality", provided they are used in the environments in which they evolved. Heuristics do not always work well, of course, and Kahneman (2003) has pointed to some of the poor results that can arise from them.

Heuristic, procedural, or ecological rationality stands in contrast to substantive rationality and "the canonical definition of rational inference as weighting and adding of all information (as long as it is free)" (Gigerenzer/Brighton 2009, 113). Clark (1997) referred to this as "compositional analysis" - conscious problem-solving that applies computation to the complete set of available evidence. Of course, obtaining "all information" is never free, and neither is the effort required to process it (Gigerenzer/Brighton 2009). These heuristics predate and frequently supervene decision-making in the substantively rational, inferential mold (Haidt 2001; Mercier/Sperber 2011), and there is ample evidence of "automatic" cognition regarding goals, evaluations, and emotions (Bargh et al. 1999).

In sum, some models of classical pragmatics rely upon a rationalist assumption about human conduct, that humans use substantively rational inference to interpret communication and that the object of their interpretations is propositional content. But human language and cognition are subject to a wide variety of heuristics and cognitive biases that suggest substantive rationality does not govern utterance interpretation. 


\section{Relevance-theoretic pragmatics}

In 1986, linguist Deirdre Wilson and anthropologist and cognitive scientist Dan Sperber published the first edition of Relevance: Communication \& Cognition; the second edition followed in 1995 (Sperber/Wilson 1995). Since its introduction, Sperber and Wilson's relevance theory has become a mainstream theory in linguistic pragmatics, particularly in experimental pragmatics, which employs empirical methods rather than philosophical speculation for pragmatic theory building. ${ }^{7}$

I contend that Sperber and Wilson's relevance theory (RT) provides a considerably more rhetorical model of pragmatics than classical pragmatics, and it addresses some of the concerns with classical pragmatics. RT has nevertheless found little welcome in the field of rhetoric. This may be due in part to antipathy expressed by Sperber and Wilson toward the rhetorical tradition. For example, in Sperber and Cummins (2007) Sperber wrote in a footnote crediting influences: "I will name no rhetoriticians [sic] here, for it was precisely to free myself from their influence that I undertook this work." Harris (2007, 359), writing in a rhetoric journal, quoted Sperber and Wilson as saying "If relevance theory is right, then [...] rhetoric has no subject matter to study, or to teach." Nevertheless, I claim that RT goes far toward bridging the gap between rhetoric and pragmatics.

Sperber and Wilson proposed relevance theory (RT) as a cognitive theory of language-in-use. Sperber and Wilson (1995) claimed that the effort to interpret an utterance is balanced against its positive cognitive effects. The more positive cognitive effects a stimulus has, the more relevant it is; the more difficult to process a stimulus is, the less relevant. It is this relationship that Sperber and Wilson (1995) refer to as "relevance" in the context of human communication: The greater the utility and the lesser the effort to interpret, the greater the relevance (see also Wilson/Sperber 2004; 2012). They argued that "the search for relevance is a basic feature of human cognition, which communicators may exploit” (Wilson/Sperber 2004, 608).

According to Wilson and Sperber $(2004,607)$, “[t]he central claim of relevance theory is that the expectations of relevance raised by an utterance are precise and predictable enough to guide the hearer toward the speaker's meaning". "The universal cognitive tendency to maximize relevance makes it possible (to some extent) to predict and manipulate the mental states of others" (Wilson/ Sperber 2004, 611). In other words, it is not necessary to assume or accept Grice's Cooperative Principle. In fact, Sperber and Wilson (1995) expended considerable effort to show that Grice's CP is neither a necessary nor a sufficient condition for communication and interpretation.

7 See Yus (2017) for a massive, thematically categorized bibliography of citing works. 
Wilson and Sperber have developed their theory more fully in extended works on the subject (Sperber/Wilson 1995; Wilson/Sperber 2012). An accessible and useful summary of RT appears in Wilson and Sperber (2004). And Padilla Cruz (2016) offers a recent collection assessing the legacy of RT and its potential future, including some of the modifications I discuss below. But central here are several concepts that I will discuss briefly.

Wilson and Sperber $(2004,612)$ proposed that a Hearer confronted with an ostensive communicative stimulus ${ }^{8}$ employs the relevance-theoretic comprehension (or interpretation) procedure:

(9) Follow a path of least effort in computing cognitive effects: Test interpretive hypotheses (disambiguations, reference resolutions, implicatures, etc.) in order of accessibility.

(10) Stop when your expectations of relevance are satisfied (or abandoned).

Note that for Wilson and Sperber, the effect side of the relevance calculation, represented by "cognitive effects" in the comprehension procedure, is measured by an increase in the Hearer's store of assumptions - that is, by the true representations about the world that can be stated in propositional form and that the Hearer can infer from the Speaker's utterance, though not all RT theorists agree that increasing the Hearer's store of assumptions is the only purpose of communication (e.g., Piskorska 2016, 293). This constraint on RT ignores the fact, taken up below, that some assumptions will be more important to the Hearer than others, depending on what his goals are for the communicative interaction, and some RT theorists appear to admit goals as an influence on interpretation (e. g., Oswald 2016; Straßheim 2010). What's more, this constraint ignores important aspects of everyday communications, like phatic communications intended not to communicate information but to enhance the affiliation between Speaker and Hearer or to create an emotional response in the Hearer that cannot easily be summarized in propositional form. Piskorska (2016, 289) characterizes these as "perlocutionary effects"9 of speech, effects of a "cognitive or affective type induced intentionally in the hearer by the speaker producing an utterance". We will also take these up below.

In any event, under the relevance-theoretic comprehension procedure, the easy interpretation should be the first; and by definition, it will be the best (though it might not be correct). This approach is consistent with the cognitive heuristics called "take-the-best" and "satisficing” by Gigerenzer and Brighton (2009, 130).

8 By ostensive communicative stimulus, Wilson and Sperber refer to one "designed to attract an audience's attention and focus it on the communicator's meaning” (Wilson/Sperber 2004, 611). 9 The term of Austin (1975), of course. 
As noted above, Grice (1989) called for the utterance to be decoded and then the inferential process to apply only where necessary. Sperber and Wilson, in contrast, claimed that even the decoding process requires inferences about disambiguation of word senses and reference resolution, what they call "explicatures" or "identification of explicit content" (Wilson/Sperber 2004, 615). For example, for Marc to interpret "La plume de notre tante est sur le bureau" (2), he must resolve references like notre tante "our aunt", especially if they have more than one aunt, and le bureau "the desk", where contextual factors must provide necessary information for Marc to conclude which desk.

Importantly, Wilson and Sperber imagined a series of subtasks of the first step of the comprehension procedure in (9) to happen simultaneously and for the results of this "online" comprehension procedure to influence each other, listed in (11) through (13) (Wilson/Sperber 2004, 615).

(11) Identify explicatures through "decoding, disambiguation, reference resolution, and other pragmatic enrichment processes".

(12) Construct "an appropriate hypothesis about the intended contextual assumptions (implicated premises)".

(13) Construct "an appropriate hypothesis about the intended contextual implications (implicated conclusions)".

RT takes all these subtasks as requiring inference and as taking place simultaneously. The Hearer does not decode "literal meaning" or "what is said" first and only then apply inference.

One advantage of this approach is that RT does not have to regard metaphor and irony as exceptional or as arising only from a clash between or flouting of Gricean maxims. For example, when Bill asks "What do you think of Smith's new German textbook?” (5) and Anne answers “Où est la plume de ma tante” (6), Bill could likely recognize from Anne's body language and tone of voice that her utterance was meant to be sarcastic or ironic and that he should not seek a literal interpretation of what she is saying (which would be a waste of interpretive effort in any event). Wilson and Sperber would maintain that Bill reaches this interpretation by mutual adjustment of the explicit and implied content in the utterance and that this is exactly the same method that any Hearer uses to interpret any other utterance, including "strictly literal interpretations" (Wilson/Sperber 2012, 108). In this sense, literal interpretations are not in any way an initial default.

The relevance theory of Wilson and Sperber addresses some of the concerns about classical pragmatics raised above. RT shifts away from a preference for decoding, still evident in classical pragmatics, and offers decoding and infer- 
ence as parallel processes operating online rather than one before the other. These moves lead to more cognitively efficient interpretation. Notably, RT dispenses with the Cooperative Principle of Grice as unnecessary, removing an impediment to the bridge between pragmatics and rhetoric identified in Dascal and Gross (1999) and Liu and Zhu (2011). But other concerns discussed above remain: RT focuses only on the propositional content of utterances, without attention to Speaker's and Hearer's goals and emotions. This is important both from the perspective of production, where RT does not acknowledge that the Speaker's goals may involve changing the Hearer's emotions and goals as much as his assumptions or beliefs about the world, and interpretation, where RT views the work of interpreting utterances as still being substantively rational, without considering the "procedural" rationality of cognitive heuristics or the effect of the Hearer's goals and emotions on his interpretation. Finally, Wilson and Sperber's work seems strongly focused on relevance-theoretic comprehension or interpretation, without giving much attention to the production of communicative performances. The work of several scholars begins to address these concerns.

Straßheim (2010), based on the work of Alfred Schutz (1973), focused attention on the Speaker/Writer's production of utterances; on the concept of "typification”, which can be seen as a habitual cognitive response to a repeated context; and on the consideration of things other than assumptions as constituting cognitive effects, including especially the Speaker's goals. Schutz's theory of typification has played an important role in contemporary rhetorical theory (Bazerman 2013; Miller 1984). Straßheim (2010, 1413) argued that Schutz's typification is grounded in the concept of relevance, and that Schutz's relevance-theoretic perspectives on communication complement those of RT. Straßheim quoted Schutz: "The concept of relevance is the central concept of sociology and of the cultural sciences."

The theory of Straßheim (2010) makes three important contributions. Though he did not identify it as one of his major contributions to relevance theory, I propose that Straßheim's first contribution was to focus considerable attention on the Speaker's production of optimally relevant utterances, rather than only on the Hearer's interpretations. This marks an important difference from RT, which consistently focuses on the Hearer's interpretive processes but neglects the processes of production, the realm of rhetoric. Straßheim (2010, 1419; emphasis mine) wrote: "Since the intended experience is highly selective, the communicator should, in her own interest, attempt to suit her communicative means and ends to her addressee's dynamics of selections, i.e. she should somehow diagnose and prognosticate what is relevant to her addressee under which circumstances.” Unfortunately, Straßheim did not offer 
a relevance-theoretic explanation of how the Speaker produces her utterance; I have extended his work to do so below.

Straßheim's second useful addition to relevance theory was an understanding of how a Speaker could predict what the Hearer will find to be relevant. In his view, "a relevance theory of communication needs to say more [than RT does] about how people know what would be relevant to others" (Straßheim 2010, 1422). This is true given that we cannot have entirely congruent experiences. ${ }^{10}$ As a solution, Straßheim $(2010,1423)$ proposed Schutz's theory of typification, an idealization that there is "a congruency of the systems of relevances" in Speaker and Hearer, summed up by this quotation from Schutz:

Until counterevidence [sic] I take it for granted - and assume my fellow-man does the same that the differences in perspectives originating in our unique biographical situations are irrelevant for the purpose at hand of either of us. (quoted in Straßheim 2010, 1423)

The idealization comes with a recognition that the counter-evidence Schutz mentioned could come at any time, and that if a Speaker or Hearer fails to recognize the counter-evidence, a miscommunication is possible or even likely. Schutz and Straßheim noted that Speakers and Hearers in most cases must immediately abandon the idealized similarity between them, but only to the extent that the evidence of their context and communications demands it. In other words, Speaker and Hearer will rely heavily on habitual performances and interpretations, barring counter-evidence that suggests they should vary from habitual practices. This is consistent with the "fluency heuristic" described by Gigerenzer and Brighton (2009, 130).

Straßheim's third useful addition to relevance theory was to argue that its definition of "cognitive effects" as alterations in the Hearer's store of assumptions was too "constrained to an inferential logic of assumptions". He saw that "Sperber and Wilson strictly define the 'effect' side of relevance (which shapes the whole notion) in terms of either deducing new assumptions, modifying the strength of old ones, or erasing old ones" (Straßheim 2010, 1432). Recall from above that "assumptions" are representations about the world that can be stated in propositional form. Straßheim claimed that such a limitation results in relevance theory failing to account for enough of what goes on in communication and contrasted it with the theory of Schutz, which considered "practical planning and acting" and emotions as important inputs to the relevance assessment (Straßheim 2010; see also Larson 2016; Oswald 2016; Piskorska 2016).

10 And if we did, as Straßheim noted, there would be no need for communication. 


\section{Cognitive pragmatic rhetorical theory}

Like the work of Wilson and Sperber, one of the goals for cognitive pragmatic rhetorical (CPR) theory is to offer a framework for describing human communicative activity in a way that can effectively be explored empirically. Essentially, CPR theory seeks to build a cognitive bridge between rhetoric and pragmatics, and particularly experimental pragmatics. It does so by synthesizing RT and adaptations of it by RT theorists described above.

In brief, CPR theory explains how Speakers and Hearers produce and interpret utterances subject to the principle of relevance, which I describe metaphorically as a fraction with cognitive effect in the numerator and cognitive effort in the denominator. Cognitive effects consist of assumptions, or factual representations, and emotions that are consistent with the Hearer's goals and which the Hearer may derive from an utterance by means of substantively rational inference - taking into account linguistic decoding, contextual information, and expectations about the Speaker's intended effects - application of cognitive heuristics, or both. Cognitive effort consists of the effort required to engage in rational inference as well as search costs, the effort required to make interpretive resources accessible in the Hearer's cognitive environment. The CPR relevance fraction emphasizes that as the cognitive effect grows, so too does relevance, and as the cognitive effort grows, relevance declines, just as the numerator and denominator of a fraction affect its evaluation.

To flesh out CPR theory, I will connect these cognitive and pragmatic dimensions to rhetoric. First, I examine the components of the cognitive environments for Speakers and Hearers. Cognitive environment is a concept in RT that refers strictly to the assumptions that Speakers and Hearers hold. CPR theory adapts this concept by expanding the meaning of assumption and by including the Speaker's and Hearer's goals and emotions.

Second, I explain how CPR theory extends the idea of cognitive effort (or accessibility) by recasting it to include search costs: the effort a Hearer spends to find productive or interpretive resources not presently accessible in his or her cognitive environment. The greater these search costs, the greater the effort in the effect-effort fraction that defines relevance, and the more likely the Hearer will not interpret the utterance as the Speaker desires.

Third, I show how the Speaker's cognitive environment connects to the Hearer's cognitive environment by describing CPR theory's notion of imputed cognitive environment. This can be seen as the construction of the audience by a speaker (or vice versa), consistent with some contemporary theories of rhetoric (e. g., Perelman/Olbrechts-Tyteca 1969). Finally, I illustrate the CPR-theoretic production and interpretation processes using the examples with which this chapter opened and with an attested rhetorical performance. 


\subsection{Components of cognitive environments}

A central component of a human's communicative production and interpretation is the human's “cognitive environment”, which I define this way:

(14) Cognitive environment (CPR): For an individual at a given time, the union of the set of assumptions and goals accessible to him or her and his or her emotional state.

I define each of these components and explain why it is included in this definition below. This definition of "cognitive environment" differs from Sperber and Wilson's. In RT, the cognitive environment includes only assumptions, but I reject both RT's limited definition of "assumption" and its restriction of the cognitive environment only to assumptions.

\subsubsection{Assumptions}

In CPR theory, assumption is defined as follows:

(15) Assumptions (CPR): Thoughts that can be expressed in propositional form and are treated by the individual as representations of the world, including the states of mind of the individual or others (meta-representations) and including hypothetical propositions.

Recall that for RT, assumptions are beliefs with propositional content. Sperber and Wilson (1995, 2) define "assumptions" as "thoughts treated by the individual as representations of the actual world (as opposed to fictions, desires, or representations of representations)".

Sperber and Wilson conclude that assumptions can be presented in propositional form. For example, the moment Cyrille responds "La plume de notre tante est sur le bureau” (2) to Marc's question “Où est la plume de notre tante?” (1), Marc may entertain a representation such as (16), (17), or (18) or some combination of them.

(16) 'The pen is on the table.'

(17) 'Cyrille just told me the pen is on the table.'

(18) 'Cyrille wants me to believe that the pen is on the table.'

On Sperber and Wilson's account, though, (18) is not an assumption but a representation of a representation, or a meta-representation. Nevertheless, as such 
hypothetical and meta-representations are the inputs and outputs of communication, I will not exclude them. ${ }^{11}$

For Speaker and Hearer alike, contextual assumptions are critical for interpretation, including (A) "encyclopedic knowledge about the world", ${ }^{12}$ (B) knowledge speaker and hearer have about each other, (C) knowledge of events that have just transpired in a shared environment, (D) knowledge of previous utterances witnessed by them, (E) non-verbal cues like smiles, winks or tone of voice, (F) knowledge of linguistic cues, and (G) the physical environment (Yus 2016, 150-154).

CPR theory recognizes at least two attributes of assumptions that are important in their application: An assumption can be more or less accessible to the individual, and an individual can be more or less committed to an assumption. See the discussion below of accessibility and commitment.

\subsubsection{Goals}

Having addressed assumptions, we can turn now to goals. As a preliminary definition of "goal” for CPR theoretical purposes, I offer (19):

(19) Goals (CPR): Consequences (end states or otherwise) desired or unwanted by a human and capable of motivating him or her to action. ${ }^{13}$

Goals are not a feature of the cognitive environment in RT (cf. Larson 2016; Oswald 2016). Straßheim (2010) made an important contribution by noting that the calculation of "relevance" is difficult or impossible without accounting for the goals of the individual, but he did not offer a definition of "goal". This chapter is no place

11 Sperber might conclude that cognition relating to utterances and thoughts (all metarepresentations) would be handled by a different mental module under his massive modularity hypothesis, under which there are distinct mental modules for communication, argumentation, etc. Ultimately, it is not necessary for purposes of CPR theory's goals of analysis and interpretation to distinguish these modules, though it might prove helpful for empirical research in the future. The same is true, for example, with regard to the possibility that there is a mental model for automatic (affective) evaluations of stimuli (Bargh et al. 1996, 123) in relation to my inclusion of emotions in the cognitive environment.

12 Not necessarily true information, but what is commonly believed - doxa or endoxa, in classical rhetorical terms.

13 Adapted from Gutman (1997, 547), internal citations omitted. Future study of goals in this context probably needs to explore the way that goals - what we want or don't want - are shaped by values - why we want or don't want those outcomes (Gutman 1997). 
to offer a complete theory of goals for human action, but it seems necessary to offer at least the tentative definition above (adapted from the realm of marketing psychology) that can be subjected to future refinement.

Goals can be more or less accessible just as assumptions can; that is, the individual may or may not have a particular goal "in mind" during a particular communicative interaction. Like assumptions, goals are also subject to varying degrees of commitment.

\subsubsection{Accessibility, search costs, and commitment}

Goals that are accessible to an individual influence the way that she processes information (Peterman 1997). So, too, do accessible assumptions (Bargh et al. 1996, 105). But what does it mean to say that an assumption or goal is "accessible”? For a start, it means to acknowledge that it is possible for an individual to have assumptions and goals that are not influencing her present cognition to the full extent possible.

This leads (finally) to a tentative definition of "accessible" in CPR theory:

(20) Accessible (CPR): An assumption or goal is more accessible than another if it presently exerts greater influence on information processing and decision-making, or can be made to do so with lower search costs, than the other assumption or goal.

So, as Bargh et al. $(1996,105)$ explain:

The accessibility of knowledge is a function of how recently it has been used and also of how frequently it has been applied in the past [...] Frequently used or chronically accessible knowledge exerts a greater influence on judgment than does other relevant but less accessible knowledge regardless of whether it has been recently used or not; it is in a relatively permanent state of increased activation.

To this, I would add assumptions (and goals) derived from or driven by a cognitive heuristic (à la Gigerenzer/Brighton 2009) or an automatic process (Bargh/ Chartrand 1999).

An important way to conceive of accessibility of goals or assumptions not presently accessible is to think of it in terms of "search costs": A goal or assumption is more accessible where the individual needs to search less in memory for it or to engage in less inferential reasoning to derive it. For readers who are language teachers, exposure to Anne's utterance "Où est la plume de ma tante" (6), in response to a question having nothing to do with aunts or pens, will "prime" assumptions related to phrasebooks, low-quality language instruction, etc. This 
is consistent with research in "semantic priming" (see Hutchison et al. 2013, for an overview of this literature) and evaluative priming (Bargh et al. 1996). For most individuals, mentioning their goals will prime them, I believe, making them more available to influence interpretation.

At this point, I want to return to the concept of the heuristic. Above we considered the heuristic as a "fast and frugal" means of reaching a conclusion, one that operates more or less automatically in human cognition and which might or might not be justified on rational grounds. This type of cognitive heuristic has sometimes been called a cognitive bias. ${ }^{14}$ I equate search costs with the costs of finding an assumption in memory or through inference. The cognitive heuristics discussed above refer to low-cost methods for finding assumptions. But Straßheim also identifies another source for low-cost searching: typification, those "connections ingrained through repetition and automatization, [...] relatedness framed by routines or habits, [and] the continuation of what went on before" (Straßheim 2010, 1426). This is consistent, too, with Bargh et al.'s $(1996,105)$ "chronically accessible" representations, which "become active upon the presence of relevant environmental information".

Accessible goals and assumptions are "highly salient information that is constantly and automatically being strengthened" (Yus 2016, 158).

Contrast the notion here of accessibility of an assumption with an individual's commitment to it. For example, the assumption 'The pen is on the table' (16) may be one to which Marc is only tentatively committed on the basis of the fact that Cyrille has told him where the pen is. He may conclude that she could have uttered "La plume de notre tante est sur le bureau" (2) out of indifference and with no knowledge; or even in an active attempt to mislead him. Thus, the assumptions 'The pen is on the table' (16) and 'Cyrille just told me the pen is on the table' (17) may be equally accessible to Marc at the same time that he is committed more to (17) than to (16).

\subsubsection{Emotional states}

Rhetoricians since Aristotle have overtly recognized the role of emotion in communication and persuasion. Among his three artistic proofs was pathos, or appeal

14 The senses of the word "heuristic" include "[d]esignating or relating to decision making that is performed through intuition or common sense" - a sense consistent with that discussed above but also the sense "[o]f, relating to, or enabling discovery or problem-solving” (Oxford English Dictionary, n.d.). The word's etymology goes to the Greek euriskein, "to find" (Oxford English Dictionary, n.d.). This is the same root as for the term "heuresis", the Greek name for the first rhetorical canon, called "inventio" in Latin or "invention". 
to emotion (Aristotle 2007). Dascal and Gross (1999) suggested, rightly I think, that rhetoric and pragmatics need to account for emotion in the production and interpretation of communicative performances. They limited that assertion, though, to claiming that the emotional aspects of communication should be subject to rational inference. I believe it's important to distinguish the conception of emotional states and their effects on the production and interpretation of communication from assumptions about emotional states, which can be the objects of rational inference.

Consider the exchange where Carlos asked "Where is Aunt Luisa's Mont Blanc pen?" (3). Laura responded "La plume de ma tante est sur le bureau” (4). Laura's goal here was not to communicate needed information to Carlos. Instead her response in French, a language she and Maria speak but that Carlos does not, can be seen only as an effort to embarrass Carlos or make him angry in front of Maria. At this point, Carlos might feel embarrassed or angry. On the other hand, if he is used to Laura's efforts to anger him, he might not have those feelings at all. Thus he may (or may not) adopt any of the following assumptions:

(21) 'I feel angry and embarrassed.'

(22) 'Laura's comment has made me angry and embarrassed.'

(23) 'Laura intended her comment to make me angry and embarrassed.'

These assumptions can be the objects of rational inference. For example, once Carlos adopts (21) and (22), he might rationally infer (23) - though they by no means compel it. The feelings Carlos is experiencing can affect his cognition in a wide variety of ways. For example, anger and embarrassment may cause him to stomp out of the room in a huff. But note that Carlos may experience the feelings of anger and embarrassment without adopting any of the assumptions in (21) through (23), and that he might adopt the assumption (23) without actually feeling angry or embarrassed.

The effect of the Speaker's utterance on the emotions the Hearer experiences is therefore distinct from the assumptions that the Hearer has about his emotions. CPR theory maintains this distinction by evaluating emotions as cognitive effects in their own right, separately from any assumptions or propositions about them.

\subsubsection{Imputed cognitive environments}

A person interacting with another person adopts assumptions about what the other's cognitive environment includes. In other words, a Speaker has expectations about what assumptions and goals are accessible to the Hearer and what 
emotions he is experiencing. These assumptions by an individual about the cognitive environment of another I call "imputed cognitive environments".

This concept is modeled after the "mutually manifest" cognitive environment of RT, but I have avoided the terminology from RT. The name "mutual manifestation" suggests that the Speaker and Hearer actually share assumptions and that they know they share them. Sperber and Wilson (1995) took pains to clarify that this is not the case: What is mutually manifest between Speaker and Hearer may be different for Speaker and Hearer. In other words, what the Speaker thinks the Speaker and Hearer both believe may be different than what the Hearer thinks they both believe. Thus I believe the "mutually manifest" name is unnecessarily confusing and have chosen "imputed" cognitive environment instead. This conception of a mutually shared environment imagined by one party to it is consistent with the conception of audience in Perelman and Olbrechts-Tyteca (1969): They note that for a speaker, her audience is always a construction of her own, based on what she knows (or thinks she knows) about the audience.

A human may construct an imputed cognitive environment with relation to another human (or group of them) based upon a variety of assumptions and stimuli, including the contextual information identified by Yus above. For example, if two humans are interacting in a typified situation, each can be expected to understand the underlying assumptions held by the other. But as Schutz noted, they cannot have had the same experiences of even these typified environments, so their imputed cognitive environments cannot be entirely congruent.

\subsection{CPR-theoretic production and interpretation}

Under CPR theory, I argue that the production and interpretation of utterances is governed by relevance, but I propose a slight alteration to the formulation of the concept of relevance. As with Sperber and Wilson's relevance theory (RT), relevance in CPR theory is a metaphorical ratio of effect to effort. But the workings of this ratio are slightly different for the Speaker than for the Hearer. This section introduces the CPR-theoretic production and interpretation procedures.

A Speaker seeks by her utterance to change the cognitive environment of the Hearer. The changes the Speaker seeks to work on the Hearer's cognitive environment will depend on which of the Speaker's goals are most accessible to her when she is speaking and the strength of her commitment to them. The Speaker's cognition is governed by the principle of relevance. She seeks to maximize the ratio of effect to effort. So I offer the CPR-theoretic production procedure: 
(24) CPR-theoretic production procedure: The Speaker should incur search costs in producing her utterance proportional to the effect she expects it to have on the Hearer's cognitive environment, taking into account the imputed cognitive environment, the Hearer's likely assessment of the utterance's relevance to the Hearer himself, and the accessibility and strength of the goal the Speaker is attempting to advance.

This procedure was implicit in Larson (2016)'s analysis of students' writing production. He suggested that students expended considerable effort keeping the linguistic conventions of a professional genre accessible in their cognition while suppressing “chronically accessible" practices associated with the authors' genders. The students did so, he suggested, because they had highly accessible goals to which they were strongly committed: getting good grades on the assignments and making positive impressions on faculty. The goals warranted high search costs and overcoming the usually-high relevance of habitual communicative performances.

Relevance for the Hearer consists of the ratio of effects to efforts, too. But unlike RT, CPR theory does not hold that a Hearer's assessment of cognitive effects is limited to the enhancement of the assumptions available to the Hearer. On the contrary, CPR theory acknowledges that the Hearer may be engaged in the communicative exchange to obtain something more or other than information. CPR theory also measures the Hearer's effort in terms of search costs: For example, the greater the extent to which he can identify the Speaker's utterance as an example of a habitual utterance pattern, the lower the effort required to interpret her utterance.

However, because the Hearer can presume that the Speaker has attempted to make her ostensive communication optimally relevant to him, he can continue generally to rely on the RT comprehension procedure, which directs him to follow a path of least effort in interpreting the utterance and to stop when his expectations of relevance are met. (See the discussion regarding Wilson and Sperber's relevance-theoretic comprehension procedure in (9) and (10) above.) The CPR theoretic interpretation procedure accounts for the accessibility and commitment of the Hearer's goals, though, and can thus be defined this way:

(25) CPR-theoretic interpretation procedure: The Hearer should follow the path of least effort in interpreting the Speaker's utterance, testing interpretative hypotheses in order of accessibility, stopping when his expectations of relevance are satisfied, taking into account the imputed cognitive environment and the goals the Hearer is attempting to advance. 


\section{Analyses of illustrative examples}

CPR theory accounts for the examples with which this chapter opened, a partial analysis of which I offer here. Assume that after Marc uttered "Où est la plume de notre tante?" (1), Cyrille's cognitive environment consists (at least in part) of the following assumptions, goals, and emotions ${ }^{15}$ :

(26) A(ssumption): 'Marc just asked where our aunt's pen is.'

(27) A: 'The pen is on the desk.'

(28) G(oal): To aid, or at least not to hinder, Marc.

(29) E(motion): Desire to help, or at least none to harm, Marc.

Cyrille's goals and emotions probably pre-date Marc's question, and her assumptions are easily derived from asking the contextual questions suggested by Yus above. As for the cognitive environment Cyrille imputes to Marc, that includes probably at least the following:

(30) !A [That is, he does not have this assumption]: 'The pen is on the desk.'

(31) G: To know where the pen is.

(32) G: To get the pen, probably relatively quickly.

She may attribute any number of other goals and emotions to Marc, but this will suffice for now. Given her cognitive environment, the utterance that requires the least effort for her to produce and optimally achieves her goals is "La plume de notre tante est sur le bureau" (2). ${ }^{16}$ As noted above, Marc's interpretation requires merely decoding the words.

Let's assume that Laura's cognitive environment after Carlos asks "Where is Aunt Luisa's Mont Blanc pen?” (3) looks something like this:

(33) A: 'Carlos just asked where our aunt's pen is.'

(34) A: 'The pen is on the desk.'

(35) A: 'Carlos pronounces Mont Blanc that way because he is pompous.'

(36) A: 'Maria heard Carlos' question and will hear my response.'

(37) G: To put Carlos in his place by annoying or frustrating him.

15 In these analyses, components of speakers'/hearers' cognitive environments are designated as ' $A$ ' for assumption, ' $G$ ' for goal, and ' $E$ ' for emotion. An exclamation mark before the abbreviation indicates that the actor does not have that component. For example, "!A: 'The pen is on the desk"' signifies that the actor does not possess the assumption, 'The pen is on the desk.'

16 It's possible that just "Sur le bureau" would have been even better. 
(38) G: To amuse Maria or to invite her into a conspiracy against Carlos.

(39) !G [That is, she does not have this goal, though we need not assume she opposes this goal]: To help Carlos.

(40) E: Playfulness, aggression, perhaps, toward Carlos.

She might impute to Carlos a cognitive environment that includes (30)-(32). Given her goals and emotions, it's worth it for Laura to search for and construct the French response to Carlos's question, even though she would find it easier as a native speaker of English to respond in English. If we remove (37) and (38) as goals, though, that effort would make no sense, and her response would more likely be "on the desk".

For his part, Carlos will impute to Laura less-than-charitable goals if she utters "La plume de ma tante est sur le bureau" (4) in a language he does not understand, especially if she delivers it in an exaggerated or pompous tone of voice. He need not spend any more time decoding or interpreting her utterance, because he can conclude that she means it to be impenetrable to him. If he can master his own emotions, though, he might recognize the word "bureau", a cognate in English and French, and get the answer he needs. Whether he does that or instead stomps out of the room probably depends on the strength of his goals (31) and (32) (assuming those are indeed his goals).

Finally, after Bill asks “What do you think of Smith's new German textbook?” (5), Anne might have this cognitive environment:

(41) A: 'Bill just asked what I thought of Smith's text.'

(42) A: 'Smith's text is superficial and useless.'

(43) A: 'Bill understands French.' [This may require search costs for Anne, depending on how familiar she is with Bill's knowledge of languages.]

(44) A: 'Smith's text is like a language book that teaches "La plume de ma tante ..."' [This probably requires her to incur search or inference costs, though she may have formulated this comparison earlier, while actually reviewing the text.]

(45) G: To answer Bill's question.

(46) G: To seem clever to Bill.

(47) G: To amuse Bill.

(48) E: Playfulness[?]

She might impute to Bill:

(49) G: To know whether Smith's text is any good.

(50) G: To be amused, or at least no opposition to it.

(51) E: Playfulness. 
Formulating her response in the form "Où est la plume de ma tante" (6) is relevant because the extra efforts to derive (43) and (44) and to utter (6) specifically address her goals (46) and (47) and gratify her emotion (48). But she has imposed a higher interpretative cost on Bill, who does not get a straight answer to his question. If Anne is wrong about Bill's cognitive environment, for example, if he does not represent (50) or (51) and strongly holds (49) as a goal, he might be impatient with her attempt at a joke, and he might fail to interpret (6) correctly, or at all.

A full analysis of these situations would likely involve a consideration of many other contextual factors, but as constructed examples, they provided few such details. Let's consider instead an attested (though perhaps apocryphal) rhetorical performance.

Joshua Norton was a peculiar presence in 19th-century San Francisco, about whom we have a number of stories, but it's difficult to say which are true and which apocryphal. He reputedly styled himself "Emperor of America and Protector of Mexico", doing so after failed businesses had left him impoverished (Ryder 1939, n.p.). He wore military-royal clothes and even printed his own money. On one occasion, he was walking after dinner and came upon a crowd of anti-Chinese demonstrators at the corner of Kearny and California Streets who were being whipped into a potentially violent frenzy by a speaker. Anticipating violence, Norton asked to address the crowd, who at first laughed that he was being allowed to do so. According to Ryder (1939, n.p.):

The Emperor, steadying himself with his heavy cane, closed his eyes and commenced reciting the Lord's Prayer. Even the hoodlums were silent, and when he asked the audience to repeat the Prayer with him, some of them joined in [...] Then he made a little speech of his own [...] When [he] requested the crowd to disperse, it did so quickly, without dissent. There were no windows broken in [...] Chinatown that night.

In this situation, Norton took advantage of contextual information and assumptions, goals, and emotions that he could impute to his audience. For example, he was no doubt aware that such "typical" gatherings often resulted in violence against the Chinese immigrant community (recent events and recent utterances). We may assume that he had a very strong and very accessible goal to prevent violence and to get the crowd to disperse. He may have believed that directly contradicting a demagogue and ordering an angry mod to disperse rarely works. So his strong, accessible goal motivated him to expend more cognitive effort to search for a rhetorical solution. If he thought of ways to calm the crowd, he might readily have come up with the Lord's Prayer. He could reasonably conclude that most of the folks of European heritage in the crowd had Christian backgrounds (knowledge of the audience). He probably knew that the Lord's Prayer is common to all Christian denominations and appears in their scriptures (Matthew 6:9-13; 
encyclopedic knowledge; knowledge of linguistic cues). He could presume that they were all familiar with the Prayer and that they associated it with contexts of quiet, contemplation, and supplication, rather than contexts of violence (knowledge of audience and of previous utterances witnessed by them). He would expect that closing his eyes while reciting the prayer would reinforce the recollection of such contexts, making them more accessible to his audience (non-verbal cues). Asking the audience to join him in reciting the prayer further functioned to evoke the context of the church, which would generally be inconsistent with violent action (knowledge of the audience and previous utterances witnessed by them).

He made his message (the perlocutionary objective of which was to calm the crowd's violent emotions and change their immediate goals to peaceful ones) relevant to the audience: He chose an utterance - the prayer - that did not directly or literally communicate its message, so interpreting it would normally require more effort from the audience. But by choosing sentences that evoked a "chronically accessible" context for the audience, Norton could take advantage of the changes his utterance (and theirs, too, when they agreed to repeat it with him) would easily work on them to calm them before he switched to a more traditional oratorical mode and asked them to disperse.

Even this little analysis is elliptical, and there is much more that can be said about this case, but it goes some way toward showing how principles of RT and CPR theory can contribute to a rhetorical understanding both of how orators might construct their utterances and audiences understand them.

\section{Looking forward}

This chapter has introduced cognitive pragmatic rhetorical (CPR) theory, which provides a framework for analysis not available in classical pragmatics, in the relevance theory (RT) of Sperber and Wilson, or in contemporary rhetorical theory. CPR theory is cognitive in that it embraces theories from cognitive science, including cognitive heuristics and automaticity and RT itself. It seeks to characterize human communication in ways consistent with the wide-ranging programs of empirical research into it.

CPR theory is overtly pragmatic in that it adopts and adapts most of the machinery of RT. It extends that machinery by synthesizing work of RT theorists who have acknowledged the need for RT to account for speaker and hearer goals in communicative production and interpretation. CPR theory contributes to RT a production procedure that explains the great efforts speakers will make to contrive a complex communicative performance when the stakes (expressed as speakers' strong and accessible goals and emotions) are high. 
CPR theory measures cognitive effect not just in terms of increasing the hearer's assumptions - or propositional knowledge about the world. By focusing on hearers' emotions and goals, on the accessibility of assumptions and goals, and on a framework for assessing accessibility, CPR theory helps to clarify what is and is not relevant in human communication for hearers. Whether a speaker's utterance will seem optimally relevant to a hearer and thus warrant interpretive effort will still depend centrally on the hearer's goals for and emotions about the exchange and the accessibility of the assumptions she will need to search to generate necessary interpretive machinery - that is, on the cognitive effort.

Finally, CPR theory is rhetorical in that it seeks to explain the available means of persuasion and the process of rhetorical production. It also seeks to make rhetoric an explanatory discipline rather than just a knack born of experience. It may permit rhetoricians not only to identify rhetorical constructs like "rhetorical situations", "identification", and "genre", but also to explain their operation in cognitive terms.

Many questions remain. CPR theory may not be consistent with the empirical findings of researchers in cognitive science and RT. A closer comparison of CPR-theoretic principles with outcomes in such studies is necessary. And despite the toy and possibly apocryphal examples analyzed in this chapter, CPR theory has not yet proven that it can provide new and useful insights to rhetorical analysis not available with other approaches. Future work will thus determine whether CPR theory is a safe bridge, allowing travel between pragmatics and rhetoric.

\section{References}

Aristotle (2007): On Rhetoric. 2nd ed. G. A. Kennedy (trans.). New York: Oxford University Press. Austin, J. L. (1975): How to Do Things with Words. 2nd ed. Oxford; New York: Oxford University Press.

Bargh, J. A.; Chaiken, S.; Raymond, P.; Hymes, C. (1996): “The Automatic Evaluation Effect: Unconditional Automatic Attitude Activation with a Pronunciation Task". Journal of Experimental Social Psychology 32:1, 104-128.

Bargh, J. A.; Chartrand, T. L. (1999): “The Unbearable Automaticity of Being”. American Psychologist 54:7, 462-479.

Bazerman, C. (1988): Shaping Written Knowledge: The Genre and Activity of the Experimental Article in Science. Madison: University of Wisconsin Press.

Bazerman, C. (2013): A Theory of Literate Action: Literate Action Volume 2. Fort Collins, CO: The WAC Clearinghouse.

Berkenkotter, C.; Huckin, T. N. (1994): Genre Knowledge in Disciplinary Communication: Cognition/culture/power. Hillsdale, NJ: Lawrence Erlbaum.

Bhatia, V. K. (1993): Analysing Genre: Language Use in Professional Settings. Harlow, Essex, UK: Longman Group UK Ltd.

Butler, J. (1997): Excitable Speech: A Politics of the Performative. 1st ed. New York: Routledge. 
Churchland, P. (1989): A Neurocomputational Perspective: The Nature of Mind and the Structure of Science. Cambridge, MA: MIT Press.

Clark, A. (1997): Being There: Putting Brain, Body, and World Together Again. Cambridge, MA: MIT Press.

Dascal, M.; Gross, A. G. (1999): “The Marriage of Pragmatics and Rhetoric”. Philosophy \& Rhetoric 32:2, 107-130.

van Eemeren, F. H.; Grootendorst, R. (2004): A Systematic Theory of Argumentation: The Pragma-dialectical Approach. Cambridge: Cambridge University Press.

Gigerenzer, G.; Brighton, H. (2009): “Homo Heuristicus: Why Biased Minds Make Better Inferences". Topics in Cognitive Science 1:1, 107-143.

Grice, H. P. (1989): Studies in the Way of Words. Cambridge, MA: Harvard University Press.

Gutman, J. (1997): “Means-end Chains as Goal Hierarchies”. Psychology and Marketing, 14:6, $545-560$.

Haidt, J. (2001): “The Emotional Dog and its Rational Tail: A Social Intuitionist Approach to Moral Judgment”. Psychological Review 108:4, 814-834.

Harris, R. A. (2007): “Foreword to 'Rudiments of Cognitive Rhetoric”. Rhetoric Society Quarterly 37:4, 357-359.

Horn, L. R. (1992): “Pragmatics, Implicature, and Presupposition”. In: W. Bright (ed.): International Encyclopedia of Linguistics. Oxford: Oxford University Press, Vol. 3, 260-66.

Hutchison, K.; Balota, D.; Neely, J.; Cortese, M.; Cohen-Shikora, E.; Tse, C.-S.; Yap, M. J.; Bengson, J. J.; Niemeyer, D.; Buchanan, E. (2013): “The Semantic Priming Project”. Behavior Research Methods 45:4, 1099-1114.

Jacobs, S. (2000): "Rhetoric and Dialectic from the Standpoint of Normative Pragmatics". Argumentation 14, 261-286.

Juarrero, A. (1999): Dynamics in Action: Intentional Behavior as a Complex System. Cambridge, MA: MIT Press.

Kahneman, D. (2003): “Maps of Bounded Rationality: Psychology for Behavioral Economics”. The American Economic Review 93:5, 1449-1475.

Larson, B. N. (2016): “Gender/Genre: The Lack of Gendered Register in Texts Requiring Genre Knowledge”. Written Communication 33:4, 360-384.

Liu, Y.; Zhu, C. (2011): "Rhetoric as the Antistrophos of Pragmatics: Toward a 'Competition of Cooperation' in the Study of Language Use”. Journal of Pragmatics 43:14, 3403-3415.

Mercier, H.; Sperber, D. (2011): "Why Do Humans Reason? Arguments for an Argumentative Theory". Behavioral and Brain Sciences 34, 57-111.

Miller, C. R. (1984): “Genre as Social Action”. Quarterly Journal of Speech 70:2, 151-167.

Nerlich, B.; Clarke, D. D. (1996): Language, Action, and Context: The Early History of Pragmatics in Europe and America, 1780-1930. Amsterdam Studies in the Theory and History of Linguistic Science. Amsterdam: John Benjamins.

Newell, A.; Simon, H. (1976): “Computer Science as Empirical Inquiry: Symbols and Search”. Communications of the Association for Computing Machinery 19, 113-126.

Oswald, S. (2007): “Towards an Interface Between Pragma-Dialectics and Relevance Theory". Pragmatics \& Cognition 15:1, 179-201.

Oswald, S. (2011): “From Interpretation to Consent: Arguments, Beliefs and Meaning”. Discourse Studies 13:6, 806-814.

Oswald, S. (2016): "Rhetoric and Cognition: Pragmatic Constraints on Argument Processing". In: M. Padilla Cruz (ed.): Relevance Theory: Recent Developments, Current Challenges, and Future Directions. Amsterdam: John Benjamins Publishing Co., 262-285. 
Oxford English Dictionary (n.d.): heuristic, n. and adj. http://www.oed.com/view/ Entry/86554?redirectedFrom=heuristic\&

Padilla Cruz, M. (ed.). (2016): Relevance Theory: Recent Developments, Current Challenges, and Future Directions. Amsterdam: John Benjamins Publishing Co.

Perelman, C.; Olbrechts-Tyteca, L. (1969): The New Rhetoric: A Treatise on Argumentation. Notre Dame, IN: University of Notre Dame Press.

Peterman, M. L. (1997): “The Effects of Concrete and Abstract Consumer Goals on Information Processing”. Psychology \& Marketing 14:6, 561-583.

Piskorska, A. (2016): “Perlocutionary Effects and Relevance Theory”. In: M. Padilla Cruz (ed.): Relevance Theory: Recent Developments, Current Challenges, and Future Directions. Amsterdam: John Benjamins Publishing Co., 287-305.

Plato (1998): Gorgias: Translated with Introduction, Notes, and Interpretive Essay. J. H. Nichols Jr. (trans.). Ithaca, NY: Cornell University Press.

Plato (2004): Gorgias. W. Hamilton; C. Emlyn-Jones (trans.). Revised edition. London: Penguin.

Ryder, D. W. (1939): San Francisco's Emperor Norton: The Story of Norton I Emperor of America and Protector of Mexico. San Francisco: Alex. Dulfer Printing and Lithographing Co.

Schutz, A. (1964): Collected Papers 2: Studies in Social Theory. A. Brodersen (ed.). The Hague: Martinus Nijhoff.

Schutz, A. (1966): Collected Papers 3: Studies in Phenomenological Philosophy. I. Schutz (ed.). The Hague: Martinus Nijhoff.

Schutz, A. (1973): Collected Papers 1: The Problem of Social Reality. 4th ed. M. Natanson (ed.). The Hague: Martinus Nijhoff.

Searle, J. R. (1970): Speech Acts: An Essay in the Philosophy of Language. London: Cambridge University Press.

Searle, J. R. (1979): Expression and Meaning: Studies in the Theory of Speech Acts. Cambridge: Cambridge University Press.

Simon, H. A. (1990): “Invariants of Human Behavior”. Annual Review of Psychology 41:1, 1-20.

Sperber, D.; Cummins, S. (2007): “Rudiments of Cognitive Rhetoric”. Rhetoric Society Quarterly $37: 4,361-400$.

Sperber, D.; Wilson, D. (1995): Relevance: Communication and Cognition. 2nd ed. Oxford: Wiley-Blackwell.

Sperber, D.; Wilson, D. (2002): “Pragmatics, Modularity and Mind-reading”. Mind \& Language 17:1-2, 3-23.

Straßheim, J. (2010): "Relevance Theories of Communication: Alfred Schutz in Dialogue with Sperber and Wilson". Journal of Pragmatics 42:5, 1412-1441.

Wikipedia (n.d.): La plume de ma tante (linguistics). http://en.wikipedia.org/wiki/La_plume_ de_ma_tante_(linguistics)

Wilson, D.; Sperber, D. (2004): “Relevance Theory”. In: L. Horn; G. Ward (eds.): The Handbook of Pragmatics. Hoboken, NJ: Wiley-Blackwell, 607-632.

Wilson, D.; Sperber, D. (2012): Meaning and Relevance. Cambridge: Cambridge University Press.

Yus, F. (2016): "Relevance theory and contextual sources-centered analysis of irony: Current research and compatibility." In: M. Padilla Cruz (ed.): Relevance Theory: Recent Developments, Current Challenges, and Future Directions. Amsterdam: John Benjamins Publishing Co., 147-171.

Yus, F. (2017): Relevance Theory Online Bibliographic Service. http://personal.ua.es/francisco. yus/rt.html 